\title{
Symptom burden and self-management in persons with chronic obstructive pulmonary disease
}

This article was published in the following Dove Press journal:

International Journal of COPD

\author{
Heidi B Bringsvor ${ }^{1,2}$ \\ Knut Skaug' \\ Eva Langeland ${ }^{3}$ \\ Bjørg Frøysland Oftedal ${ }^{2}$ \\ Jörg Assmus ${ }^{4}$ \\ Doris Gundersen' \\ Richard H Osborne ${ }^{5}$ \\ Signe Berit Bentsen ${ }^{2}$ \\ 'Department of Research and \\ Innovation, Helse Fonna HF, \\ Haugesund, ${ }^{2}$ Department of Quality \\ and Health Technology, University of \\ Stavanger, Stavanger, ${ }^{3}$ Department of \\ Nursing, Western Norway University \\ of Applied Sciences, ${ }^{4}$ Center for \\ Clinical Research, Haukeland \\ University Hospital, Bergen, Norway; \\ ${ }^{5}$ Health Systems Improvement \\ Unit, School of Health and Social \\ Development, Centre For Population \\ Health Research, Deakin University, \\ Burwood, Victoria, Australia
}

Correspondence: Heidi B Bringsvor Department of Research and Innovation, Helse Fonna HF, Postboks 2I70,

5504 Haugesund, Norway

Tel +47909382 I3

Email heidi.breistrand.bringsvor@helsefonna.no
Purpose: Self-management is crucial for effective COPD management. This study aimed at identifying associations between self-management and sociodemographic characteristics, clinical characteristics, and symptom burden in people with COPD.

Patients and methods: In this cross-sectional study with 225 participants diagnosed with COPD grades II-IV, multiple linear regression analysis was conducted, using sociodemographic and clinical characteristics and symptom burden (COPD Assessment Test) as the independent variables and the eight self-management domains of the Health Education Impact Questionnaire (heiQ) as the outcome variables.

Results: Higher symptom burden was significantly associated with worse scores in all selfmanagement domains $(p<0.003)$, except for self-monitoring and insight $(p=0.012)$. Higher disease severity $(p=0.004)$ and numbers of comorbidities $(p<0.001)$ were associated with more emotional distress, and women scored higher than men on positive and active engagement in life $(p=0.001)$. Higher score in pack-years smoking was associated with lower score in health-directed activities $(p=0.006)$ and self-monitoring and insight $(p<0.001)$, and participation in organized physical training was associated with higher score in health-directed activities $(p<0.001)$. The final models explained $3.7 \%-31.7 \%$ of variance (adjusted $R^{2}$ ) across the eight heiQ scales.

Conclusion: A notable finding of this study was that higher symptom burden was associated with worse scores in all self-management domains, except for self-monitoring and insight. In addition, sex, disease severity, comorbidity, pack-years smoking, and participation in organized physical training were associated with one or two self-management domains. The study contributes to improved understanding of self-management in COPD. However, the explained variance levels indicate that more research needs to be done to uncover what else explains self-management domains in COPD.

Keywords: COPD, Health Education Impact Questionnaire, COPD Assessment Test, selfmanagement, symptoms, chronic disease

\section{Introduction}

COPD is a preventable and treatable chronic lung disease characterized by airflow obstruction that is not fully reversible with persistent respiratory symptoms. ${ }^{1,2}$ Even with optimal medical treatment, many people with COPD experience a symptom burden consisting of multiple symptoms (ie, dyspnea, coughing, wheezing, anxiety, depression, sleeplessness, and fatigue)..$^{3,4}$ Persons with COPD must, in addition to following complex medical regimes, monitor their disease, make lifestyle changes, manage its physical and psychosocial consequences, and decide when they need to seek professional care and when they can handle problems on their own. ${ }^{1,2,5}$ Consequently, COPD is a disease involving extensive and complex self-management, 
and in the past decade, self-management support has been described as a crucial element of effective COPD management. ${ }^{6,7}$

Self-management has been defined in different ways. Previously, self-management emphasized that patients follow directions given by health care professionals and meet expectations for compliance with prescribed therapies and medical treatment. ${ }^{8}$ Recent research has indicated that selfmanagement is a multidimensional construct that consists of various domains. ${ }^{9}$ Eight independent domains describing self-management have been identified in the widely used Health Education Impact Questionnaire (heiQ): 1) positive and active engagement in life; 2) health-directed activities; 3) skill and technique acquisition; 4) constructive attitudes and approaches; 5) self-monitoring and insight; 6) health services navigation; 7) social integration and support; and 8) emotional distress. ${ }^{9}$

During the past decade, various studies investigated the relationships between demographic and clinical characteristics and self-management among persons with chronic diseases, including COPD. ${ }^{10-14}$ The findings have indicated that age, ${ }^{10,11}$ being female, ${ }^{12}$ educational achievement, ${ }^{10,12}$ social support, ${ }^{10}$ and physical health ${ }^{12}$ are positively associated with self-management, whereas no associations are found with self-management and lung function, dyspnea, body mass index, and hospitalization. ${ }^{13}$ In addition, those with a very high symptom burden have been found to score significantly lower on self-management. ${ }^{14}$ These studies, though, have employed self-management as an umbrella term and did not specifically explore the different domains of self-management.

Some studies ${ }^{10-14}$ have examined the relationships between demographic and clinical characteristics, symptom burden, and the overall experience of self-management in persons with COPD. However, to date, no studies have specified different self-management domains and investigated the relationships among demographic and clinical characteristics, symptom burden, and different self-management domains in persons with COPD. Therefore, the purpose of the present study was to examine the relationships of sociodemographic and clinical characteristics and symptom burden with different self-management domains in persons with COPD.

\section{Patients and methods}

\section{Design, setting, and procedure}

For this cross-sectional study (ClinicalTrials.gov identification: NCT02479841), 225 persons with COPD from 11 municipalities on Norway's West Coast were recruited from a hospital register between May 2014 and June 2015.
Patients were included if they were $\geq 18$ years old, were able to read and speak Norwegian, registered with one or more International Classification of Disease codes J44-0, 1, 8, or 9 after January 1, 2010, and diagnosed with COPD grades II-IV based on airflow limitation using Global Initiative for Chronic Obstructive Lung Disease (GOLD) standards. ${ }^{2}$ Patients were excluded if they had a cognitive impairment, a substantial alcohol and/or drug abuse, or a life expectancy $<12$ months. The study was performed according to the Declaration of Helsinki and approved by the Regional Committee of Medical Research Ethics (Reference No 2013/1741). Written, informed consent for participation in the study was obtained from all the participants.

\section{Measures}

\section{Sociodemographic and clinical characteristics}

Age and sex were obtained from the hospital registers, while information on education, cohabitation (living alone), comorbidity, pack-years smoking, daily use of inhaled corticosteroids (ICS), participation in organized physical training, and previous participation in pulmonary rehabilitation programs was self-reported on questionnaires. Pack-years smoking was retrospectively calculated by multiplying years smoked by the average number of cigarettes divided by 20 for ever-smokers.

\section{Lung function}

When the participants were enrolled in the study, the research nurse reviewed registered spirometries in their medical records. If a spirometry conducted according to the international standards ${ }^{15,16}$ was registered 12 months before enrollment, data on postbronchodilator forced vital capacity (FVC) and forced expiratory volume in 1 second $\left(\mathrm{FEV}_{1}\right)$ were obtained from the medical records. For participants with a spirometry more than 1 year earlier, the research nurse conducted a new test according to the international standards. ${ }^{15,16}$ Norwegian reference values were used to calculate the $\mathrm{FEV}_{1}$ percentage predicted $\left(\mathrm{FEV}_{1} \%\right) .{ }^{17} \mathrm{COPD}$ disease severity (GOLD grade) was classified by using GOLD-defined criteria: ${ }^{2}$ mild (I), moderate (II), severe (III), or very severe (IV) COPD defined as $\mathrm{FEV}_{1} / \mathrm{FVC}<0.7$, and $\mathrm{FEV}_{1} \% \geq 80 \%$ (I), $\mathrm{FEV}_{1} \%=50 \%-79 \%$ (II), $\mathrm{FEV}_{1} \%=30 \%-49 \%$ (III), or $\mathrm{FEV}_{1} \%<30 \%$ (IV), respectively. ${ }^{2}$

\section{COPD Assessment Test (CAT)}

Symptom burden was measured with the CAT, ${ }^{18}$ a diseasespecific questionnaire designed to assess the symptom burden of persons with COPD. The questionnaire consists of eight items (ie, cough, phlegm, chest tightness, breathlessness, 
activities, confidence, sleep, and energy) rated on a scale of $0-5$. Total scores range from 0 to 40 , with higher scores indicating higher symptom burden. ${ }^{18,19}$ Scores $>30$ indicate very high burden, 20-30 high burden, 10-20 medium burden, and $<10$ low burden. ${ }^{20} \mathrm{CAT}$ has been translated into various languages and shown to have satisfactory reliability and validity across European countries. ${ }^{18,19,21,22}$

\section{heiQ}

Different self-management domains were measured with the heiQ Version 2.0, a generic measurement of primarily personal self-management domains. ${ }^{9,23}$ The heiQ comprises 40 items rated on a Likert scale ranging from "strongly disagree" (1) to "strongly agree" (4). ${ }^{23}$ The items cover eight independent domains: 1) positive and active engagement in life; 2) health-directed activities; 3) skill and technique acquisition; 4) constructive attitudes and approaches; 5) self-monitoring and insight; 6) health services navigation; 7) social integration and support; and 8) emotional distress. ${ }^{9,23}$ Domains' scores are calculated by adding the score of items within scales and diving the sum by the number of items in a particular scale; hence, all domain scores range between 1 and 4. Higher scores indicate higher levels of self-management ability, except for emotional distress, where higher scores indicate more distress. The heiQ has been translated into several languages, including Norwegian, ${ }^{23}$ and shown to produce satisfactory psychometrical results across diverse settings. ${ }^{9,23-26}$

\section{Statistical analyses}

Descriptive statistics were used to characterize the sample. A three-step procedure for linear regression models was used to assess the association between each outcome measure (see above for specification of heiQ domains) and each independent variable (ie, age, sex, education level, cohabitation, comorbidities, disease severity, symptom burden, pack-years smoking, daily use of ICS, previous lung rehabilitation, and participation in organized physical training). First, the unadjusted model was fitted for each outcome and independent variable. Second, the fully adjusted model containing all the independent variables was estimated for each outcome. Finally, the final model for each outcome was defined depending on the results of the first two steps and clinical evaluations. The final models included significant variables from the first steps, as well as age, sex, and disease severity.

Assumptions of normal distribution were evaluated by graphical methods, histograms, and Q-Q plots, and the significance level was set at 0.05 . To avoid multiple comparison effects within each final model, a Bonferroni adjustment was applied. Consequently, the marginal level depended on the number of independent variables in each final model. Data were analyzed by using the SPSS Version 23 (IBM Corp., Armonk, NY, USA).

\section{Results}

Of the 649 persons who met the inclusion criteria, 225 persons consented to participate, generating a response rate of $34.7 \%$.

\section{Characteristics}

The participants' mean age was $69( \pm 8.4)$ years, and $61.3 \%$ were male. One third of the participants had primaryschool education only, 49.8\% high-school education only, and $16.9 \%$ a university education. In addition, $31.1 \%$ were living alone. Regarding disease severity, $42.7 \%$ had GOLD grade II, $40 \%$ grade III, and $17.3 \%$ grade IV. The participants' mean CAT total score was $19.1( \pm 7.5)$, and the mean number of comorbidities was $2.6( \pm 1.9)$. The mean pack-year for ever-smokers was $30.2( \pm 20.2)$. In addition, $89.1 \%$ of the participants used COPD medication, and $55.6 \%$ used ICS daily; $35.1 \%$ regularly participated in organized physical training, and $48.6 \%$ previously participated in a pulmonary rehabilitation program. Among the self-management domains, self-monitoring and insight had the highest mean score, at $3.04( \pm 0.34)$, whereas skill and technique acquisition had the lowest mean score, at $2.72( \pm 0.45)$. The mean score for emotional distress was $2.34( \pm 0.62)$. Table 2 shows the characteristics of the participants.

\section{Associations among sociodemographic and clinical characteristics, symptom burden, and self-management domains}

Table 1 shows the estimates for all the independent variables included in the final models. The unstandardized coefficients of age, sex, disease severity, and the independent variables that had significant associations $(p<0.05)$ with self-management domains in step 1 or 2 are presented. Higher COPD symptom burden was significantly associated with worse scores in all self-management domains $(p<0.003)$, except for self-monitoring and insight $(p=0.012)$. In addition, higher disease severity $(p=0.004)$ and numbers of comorbidities $(p<0.001)$ were associated with more emotional distress, and women scored higher than men on positive and active engagement in life $(p=0.001)$. Higher score in pack-years smoking was associated with less health-directed activities $(p=0.006)$ and self-monitoring and insight $(p<0.001)$, 


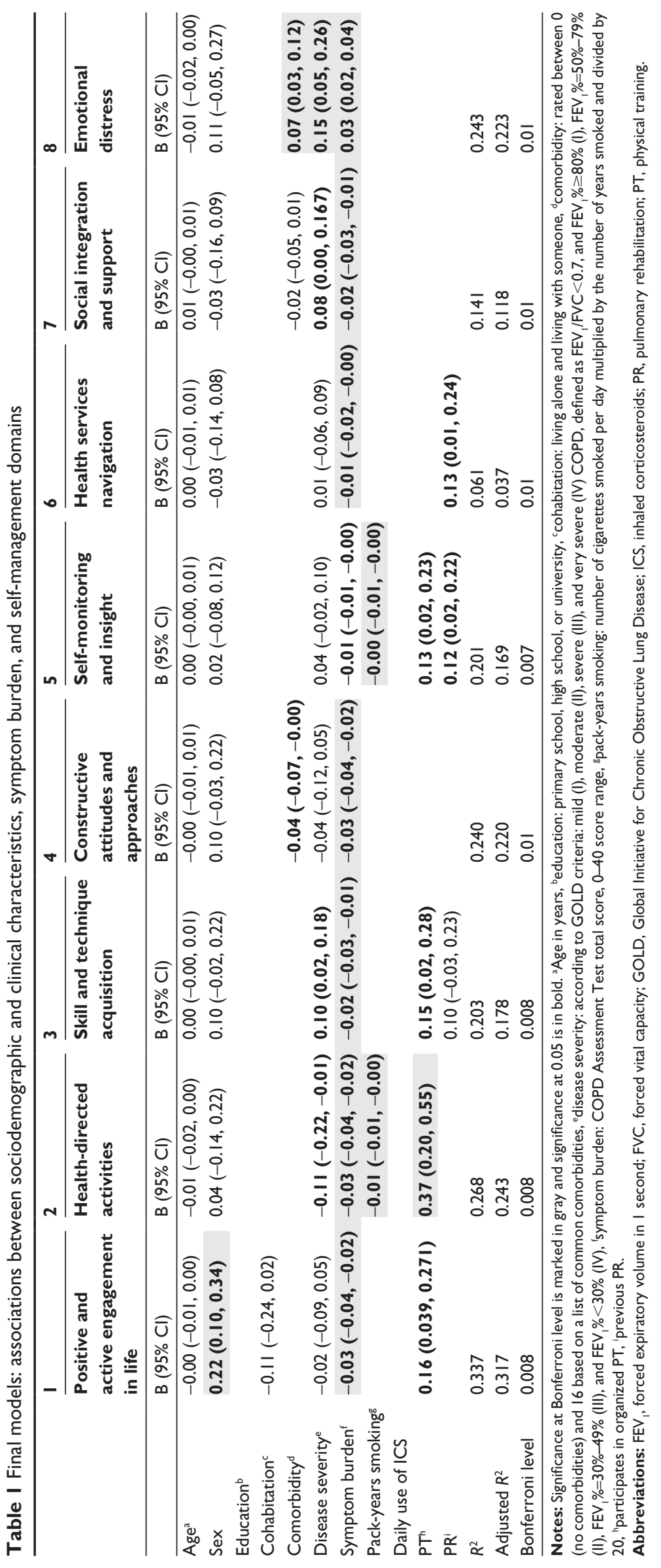


Table 2 Characteristics of the participants

\begin{tabular}{|c|c|c|}
\hline & $\mathbf{n}$ & Value \\
\hline $\mathrm{Age}^{\mathrm{a}}$ & 225 & $69.0(8.4)$ \\
\hline Sex, male & 225 & 138 (61.3\%) \\
\hline GOLD grade ${ }^{b}$ & 225 & \\
\hline GOLD II & & $96(42.7 \%)$ \\
\hline GOLD III & & 90 (40.0\%) \\
\hline GOLD IV & & $39(17.3 \%)$ \\
\hline $\mathrm{FEV}_{1} \%$ predicted $^{\mathrm{a}}$ & 213 & $45.9(14.9)$ \\
\hline Education ${ }^{\mathrm{b}}$ & 219 & \\
\hline Primary school & & $73(33.3 \%)$ \\
\hline High school & & $109(49.8 \%)$ \\
\hline University & & 37 (I6.9\%) \\
\hline Cohabitation $^{b, c}$ & 222 & 70 (31.1\%) \\
\hline Other chronic disease ${ }^{b}$ & 211 & $203(96.2 \%)$ \\
\hline Comorbidity & 210 & $2.6(1.9)$ \\
\hline Years diagnosed with COPD & 177 & $8.5(5.9)$ \\
\hline $\mathrm{BM} \mathrm{I}^{\mathrm{a}}$ & 213 & $26.3(5.8)$ \\
\hline Current smoker ${ }^{b}$ & 219 & $5 \mathrm{I}(23.3 \%)$ \\
\hline Previous smoker ${ }^{b}$ & 169 & $157(69.8 \%)$ \\
\hline Never-smoker ${ }^{b}$ & 167 & $12(5.3 \%)$ \\
\hline Pack-years, ${ }^{e}$ ever-smokers ${ }^{\mathrm{a}}$ & 186 & $30.2(20.2)$ \\
\hline CAT score $\mathrm{a}^{\mathrm{af}}$ & 215 & $19.12(7.5)$ \\
\hline mMRC score ${ }^{\mathrm{a}, \mathrm{g}}$ & 213 & $1.78(1.1)$ \\
\hline mMRC grade $0^{b}$ & & $32(15.0 \%)$ \\
\hline mMRC grade $I^{b}$ & & $57(26.8 \%)$ \\
\hline mMRC grade $2^{b}$ & & $60(28.2 \%)$ \\
\hline mMRC grade $3^{\mathrm{b}}$ & & $53(24.9 \%)$ \\
\hline mMRC grade $4^{b}$ & & II (5.2\%) \\
\hline $\mathrm{PT}^{\mathrm{b}, \mathrm{h}}$ & 225 & 79 (35.1\%) \\
\hline $\mathrm{PR}^{\mathrm{b}, \mathrm{i}}$ & 216 & $105(48.6 \%)$ \\
\hline Daily COPD medication ${ }^{\mathrm{b}}$ & 220 & 196 (89.1\%) \\
\hline Medication $^{\mathrm{b}, \mathrm{j}}$ & 225 & \\
\hline LABA $^{k}$ & & $157(69.8 \%)$ \\
\hline LAMA & & 153 (68.0\%) \\
\hline ICS & & $125(55.6 \%)$ \\
\hline SABA ${ }^{k}$ & & $125(55.6 \%)$ \\
\hline SAMA & & II (4.9\%) \\
\hline LTOT $^{\mathrm{b}}$ & 221 & $6(2.7 \%)$ \\
\hline BIPAP, & 199 & $6(2.7 \%)$ \\
\hline \multicolumn{3}{|l|}{ Self-management $\mathrm{t}^{\mathrm{a}, \mathrm{m}}$} \\
\hline I. Positive and active engagement in life & 219 & $2.9(0.5)$ \\
\hline 2. Health-directed behavior & 218 & $2.7(0.6)$ \\
\hline 3. Skill and technique acquisition & 217 & $2.7(0.5)$ \\
\hline 4. Constructive attitudes and approaches & 215 & $2.9(0.5)$ \\
\hline 5. Self-monitoring and insight & 220 & $3.0(0.3)$ \\
\hline 6. Health services navigation & 216 & $2.9(0.5)$ \\
\hline 7. Social integration and support & 218 & $2.8(0.5)$ \\
\hline 8. Emotional distress & 218 & $2.3(0.6)$ \\
\hline
\end{tabular}

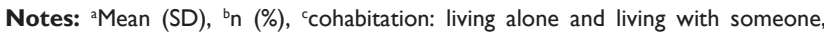
${ }^{d}$ comorbidity: rated between 0 (no comorbidities) and 16 based on a list of common comorbidities, ${ }^{e}$ pack-years: number of cigarettes smoked per day multiplied by the number of years smoked and divided by 20 , 'CAT score $(0-40)$, f $_{\mathrm{m} M R C}$ dyspnea scale (0-4), "hparticipation in organized PT: participation and no participation in PT, 'previous PR: previous PR and no previous PR, luse of medication and no use of medication, "five participants reported the use of more than one LABA, and five participants reported the use of more than one SABA, 'ventilator assistance by BIPAP, ${ }^{m}$ domains of the Health Education Impact Questionnaire (I-4).

Abbreviations: BIPAP, biphasic positive airway pressure; BMI, body mass index CAT, COPD Assessment Test; FEV ${ }_{1}$, forced expiratory volume in I second; GOLD, Global Initiative for Chronic Obstructive Lung Disease; ICS, inhaled corticosteroids; LABA, long-acting $\beta_{2}$-agonist; LAMA, long-acting anticholinergic; LTOT, long-term oxygen therapy; mMRC, modified Medical Research Council; SABA, short-acting $\beta_{2}$-agonist; SAMA, short-acting anticholinergic; PR, pulmonary rehabilitation; PT, physical training. and participation in organized physical training was associated with more health-directed activities $(p<0.001)$. The final models explained $3.7 \%-31.7 \%$ of the variance (adjusted $R^{2}$ ) across the eight heiQ scales. Further details of the first and second steps in the analysis are provided in the Supplementary material.

\section{Discussion}

This study aimed at identifying the associations of sociodemographic and clinical characteristics and symptom burden with self-management domains in persons with COPD. The most notable finding was the strong and consistent association between higher symptom burden and worse scores in all the self-management domains, except for selfmonitoring and insight. This study was the first to examine the associations between symptom burden and the various self-management domains in COPD and so has added important knowledge to the literature.

In the present study, the participants with higher symptom burden reported lower positive and active engagement in life and lower social integration and support. These domains include social interactions, motivation, and active engagement in life-fulfilling activities, sense of support from others, and social isolation due to illness. ${ }^{9}$ One possible explanation for these findings is the "vicious COPD circle," in which COPD-related pathophysiological changes and respiratory symptoms result in reduced physical activity ${ }^{27,28}$ and social engagement in life. ${ }^{29,30}$ Furthermore, the results showed that the participants with higher symptom burden reported less health-directed activities, including healthful behaviors aimed at disease prevention and health promotion (eg, walking, exercise, and relaxation). ${ }^{9,23}$ Regarding the relationship between symptom burden and physical activity, there is little evidence specific to COPD. ${ }^{2}$ However, physical activity prevents further advancement of the "vicious COPD circle," ${ }^{29}$ and general evidence that physical activity may reduce symptoms, such as dyspnea and fatigue, ${ }^{2,31}$ supports the present findings. Taken together, these findings could indicate that, in persons with COPD, high symptom burden may influence health-directed activities, social functioning, and active engagement in life.

In addition, the results showed that the participants with a higher symptom burden reported less skill and technique acquisition. Special skills and techniques are necessary to manage medication regimes in COPD, and previous studies have indicated that nonadherence to medication is common. ${ }^{32,33}$ Among the many factors associated with nonadherence, self-management-related abilities are important. ${ }^{34,35}$ Medication nonadherence is associated with 
more COPD symptoms; ${ }^{34,36}$ therefore, the present findings could be explained by increased skills and techniques, leading to improved medication adherence. It is likely that higher symptom burden results in intensified medical treatment, ${ }^{2}$ which might increase the need for the acquisition of skills and techniques. In addition, the present research found a negative association between symptom burden and health services navigation, or the ability to interact with health care professionals and organizations and to have a good understanding of ways to get one's needs met. ${ }^{9}$ High symptom burden leads to intensified treatment and interventions ${ }^{2}$ and greater support from the health care system, ${ }^{37}$ which might increase the demand for the ability to navigate health services. In addition, persons with better health services navigation abilities might receive more customized help from the health care system, affecting the symptom burden.

Furthermore, those with lower symptom burden had more constructive attitudes and approaches, which characterize the persons who attempt to minimize the effects of illness and do not let them control their lives. ${ }^{9}$ A possible explanation for this finding could be related to these efforts to reduce symptom burden. It is also possible that a response shift, or changes in an individual's internal standards and values and redefinition of target constructs, could be taking place. ${ }^{38}$ Aspects of response shift might lead to changes both in the experience of symptom burden and in attitudes and approaches.

Unsurprisingly, higher symptom burden was also clearly associated with greater emotional distress, a negative response to illness as manifested in anxiety, anger, and depression. ${ }^{9}$ This finding is supported by research showing positive associations of COPD-related symptoms with anxiety and depression in persons with COPD. ${ }^{39-42}$ The present study examined COPD symptom burden using the CAT, ${ }^{18}$ which covers symptoms related to confidence, sleep, and energy. This might overlap with the symptoms of emotional distress, anxiety, and depression. Therefore, similarities in measurement items could also explain the findings.

In the present study, the participants with more severe disease also reported greater emotional distress. This result contrasts with previous studies showing no association of disease severity, measured by GOLD grade or $\mathrm{FEV}_{1} \%$ predicted, with anxiety and depression. ${ }^{42-44}$ The link between pathophysiological changes and more anxiety and depression through reduced physical activity and negative social consequences ${ }^{27-30}$ might explain the present results showing associations of disease severity and symptom burden with emotional distress, but further research is needed. In addition, the present study showed that those with more comorbidities reported more emotional distress. This finding conflicts with a recent study finding no significant association between high numbers of comorbidities and high levels of depression. ${ }^{45}$ A possible explanation of the present findings is that $96 \%$ of the patients in this study reported one or more comorbidities, and previous studies have supported that anxiety and depression are among the most common comorbidities of COPD. ${ }^{4,46,47}$

Concerning healthy activities, the participants in organized physical training reported a higher level of healthdirected activities, whereas those with more pack-years smoking reported a lower level of health-directed activities and lower self-monitoring and insight. Although the relation of organized physical training and general physical activity in people with COPD is not well established, physical training may support increased daily physical activity. ${ }^{48}$ Furthermore, the negative association between pack-years smoking and health-directed activities aligns with a recent study finding an association between high pack-years and low physical activity levels in those with COPD. ${ }^{49}$ The negative association between pack-years smoking and self-monitoring and insight might be explained by the association of high packyears with increased respiratory symptoms ${ }^{50-52}$ and different comorbidities and complications. ${ }^{53,54}$ These findings may indicate that the overall situation for persons with COPD is complex to understand, monitor, and manage.

Finally, the present results showed that female participants reported higher positive and active engagement in life, in line with the findings of other studies. ${ }^{55}$ It is possible that the higher level of experienced psychological distress among women with COPD than men $^{56}$ might increase motivation to improve life circumstances. Another possible explanation is that women are more motivated to participate in self-management and educational programs. ${ }^{57,58}$ The findings, though, are inconclusive, ${ }^{59}$ and further research seems warranted.

Some study limitations have to be acknowledged. Symptom burden, age, sex, education level, cohabitation, disease severity, comorbidity, pack-years smoking, daily use of ICS, organized physical training, and previous lung rehabilitation explained $3.7 \%-31.7 \%$ of variance in the different selfmanagement domains. The lowest explained variance was for health services navigation (3.7\%), suggesting that navigation skills are independent of the sociodemographic, clinical, and other variables collected, while in contrast almost one third of the variance in positive and active engagement in life was explained by the model $(31.7 \%)$. These results revealed a need for better understanding of self-management domains 
in COPD and might indicate that other variables, such as hospitalization, ${ }^{11,60,61}$ coping, ${ }^{11}$ and social support, ${ }^{62}$ may account for some variance in self-management domains. However, the low explained variance could also be related to participants actually being very similar in some domains, generating low sample variation, or perhaps the heiQ does not reflect existing variability for persons with COPD. In addition, the study was mainly based on self-reported data, and the response rate was low. This study was part of a larger randomized controlled study, and those participated in this study agreed to participate in a self-management program consisting of weekly group conversations for 11 weeks. It is possible that some participants did not respond because they did not want to participate in the self-management program. The cross-sectional design makes it impossible to draw causal conclusions. However, the data suggest that almost all the heiQ domains would be useful to improve the wellbeing of people with COPD. Furthermore, only persons with moderate-to-very severe COPD from specified geographical areas were invited to participate in the present study, and by including from a hospital register, the sample might be considered a convenience sample. Therefore, the findings might not be generalizable to all persons with COPD.

\section{Implications for clinical practice}

This study indicated important associations between symptom burden and different self-management domains of COPD. The eight domains of the heiQ provide clear direction for self-management support curriculum that could be put in place to support people with COPD. Health-directed activities, skills and technique acquisition, and abilities to navigate in health services, together with positive engagement, constructive attitudes, and social and emotional aspects, were all associated with lower symptom burden and might be recognized as important to alleviate symptoms and support self-management. Self-management support programs that specifically focus on each of the heiQ domains over time might improve, in particular, symptom burden; however, intervention research is required to rule out reverse causation.

\section{Conclusion}

The present study revealed significant associations between symptom burden and all the self-management domains, except for self-monitoring and insight. In addition, sex, disease severity, comorbidity, pack-years smoking, and participation in organized physical training were associated with one or two self-management domains. The low levels of explained variance suggest a poor ability to explain and indicate that more research needs to be done to uncover what else explains self-management domains in COPD. However, the knowledge produced by this study can serve as a first step toward improved the understanding of characteristics associated with the various self-management domains in persons with COPD and indicates that the heiQ domains could provide a direction for self-management support curriculums to support self-management in people with COPD.

\section{Acknowledgments}

The authors thank Gunnar Egge for his contributions in planning the study and research assistant Mien Parlati for technical assistance in preparing the data for analysis. Western Norway Regional Health Authority has supported this study by a grant (No 2103/911836), and Richard H Osborne was funded through a National Health and Medical Research Council (NHMRC) Senior Research Fellowship (\#APP1059122).

\section{Disclosure}

The authors report no conflicts of interest in this work.

\section{References}

1. NICE. Chronic obstructive pulmonary disease in adults (update), Quality standard [QS10]. 2016. Available from: https://www.nice.org.uk/ guidance/qs10. Accessed April 2, 2016.

2. GOLD. Global Strategy for the Diagnosis, Management and Prevention of COPD, Global Initiative for Chronic Obstructive Lung Disease. 2017. Available from: http://goldcopd.org. Accessed May 10, 2017.

3. Joshi M, Joshi A, Bartter T. Symptom burden in chronic obstructive pulmonary disease and cancer. Curr Opin Pulm Med. 2012;18(2):97-103.

4. Bentsen SB, Gundersen D, Assmus J, Bringsvor H, Berland A. Multiple symptoms in patients with chronic obstructive pulmonary disease in Norway. Nurs Health Sci. 2013;15(3):292-299.

5. Barlow J, Wright C, Sheasby J, Turner A, Hainsworth J. Self-management approaches for people with chronic conditions: a review. Patient Educ Couns. 2002;48(2):177-187.

6. Disler RT, Gallagher RD, Davidson PM. Factors influencing selfmanagement in chronic obstructive pulmonary disease: an integrative review. Int J Nurs Stud. 2012;49(2):230-242.

7. Bourbeau J, Nault D, Dang-Tan T. Self-management and behaviour modification in COPD. Patient Educ Couns. 2004;52(3):271-277.

8. Bourbeau J, Bartlett SJ. Patient adherence in COPD. Thorax. 2008; 63(9):831-838.

9. Osborne RH, Elsworth GR, Whitfield K. The Health Education Impact Questionnaire (heiQ): an outcomes and evaluation measure for patient education and self-management interventions for people with chronic conditions. Patient Educ Couns. 2007;66(2):192-201.

10. Bos-Touwen I, Schuurmans M, Monninkhof EM, et al. Patient and disease characteristics associated with activation for self-management in patients with diabetes, chronic obstructive pulmonary disease, chronic heart failure and chronic renal disease: a cross-sectional survey study. PLoS One. 2015;10(5):e0126400.

11. Warwick M, Gallagher R, Chenoweth L, Stin-Parbury J. Self-management and symptom monitoring among older adults with chronic obstructive pulmonary disease. J Adv Nurs. 2010;66(4):784-793. 
12. Cramm JM, Nieboer AP. Self-management abilities, physical health and depressive symptoms among patients with cardiovascular diseases, chronic obstructive pulmonary disease, and diabetes. Patient Educ Couns. 2012;87(3):411-415.

13. Benzo RP, Kirsch JL, Dulohery MM, Abascal-Bolado B. Emotional intelligence: a novel outcome associated with wellbeing and selfmanagement in chronic obstructive pulmonary disease. Ann Am Thorac Soc. 2016;13(1):10-16.

14. Halding AG, Grov EK. Self-rated health aspects among persons living with chronic obstructive pulmonary disease. Int J Chron Obstruct Pulmon Dis. 2017;12:1163-1172.

15. Miller MR, Hankinson J, Brusasco V, et al. Standardisation of spirometry. Eur Respir J. 2005;26(2):319-338.

16. GOLD. Global Institute for Chronic Obstructive Lung Disease, GOLD Spirometry Guide. 2010. Available from: http:/goldcopd.org/goldspirometry-guide/. Accessed April 27, 2016.

17. Johannessen A, Lehmann S, Omenaas ER, Eide GE, Bakke PS, Gulsvik A. Post-bronchodilator spirometry reference values in adults and implications for disease management. Am J Respir Crit Care Med. 2006;173(12):1316-1325.

18. Jones PW, Harding G, Berry P, Wiklund I, Chen WH, Kline Leidy N. Development and first validation of the COPD Assessment Test. Eur Respir J. 2009;34(3):648-654.

19. Jones PW, Brusselle G, Dal Negro RW, et al. Properties of the COPD assessment test in a cross-sectional European study. Eur Respir J. 2011;38(1):29-35.

20. CAT Development Steering Group. COPD Assessment Test, Healthcare Professional User Guide. 2016. Issue 3: Available from: http://www. catestonline.org/. Accessed May 10, 2017.

21. Dodd JW, Hogg L, Nolan J, et al. The COPD assessment test (CAT): response to pulmonary rehabilitation. A multicentre, prospective study. Thorax. 2011;66(5):425-429.

22. Jones PW, Harding G, Wiklund I, et al. Tests of the responsiveness of the COPD assessment test following acute exacerbation and pulmonary rehabilitation. Chest. 2012;142(1):134-140.

23. Wahl AK, Osborne RH, Langeland E, et al. Making robust decisions about the impact of health education programs: psychometric evaluation of the Health Education Impact Questionnaire (heiQ) in diverse patient groups in Norway. Patient Educ Couns. 2016;99(10): 1733-1738

24. Elsworth GR, Nolte S, Osborne RH. Factor structure and measurement invariance of the Health Education Impact Questionnaire: does the subjectivity of the response perspective threaten the contextual validity of inferences? SAGE Open Med. 2015;3:2050312115585041.

25. Nolte S, Elsworth GR, Osborne RH. Absence of social desirability bias in the evaluation of chronic disease self-management interventions. Health Qual Life Outcomes. 2013;11(1):114.

26. Elsworth GR, Osborne RH. Percentile ranks and benchmark estimates of change for the Health Education Impact Questionnaire: normative data from an Australian sample. SAGE Open Med. 2017;5: 2050312117695716

27. Polkey MI, Moxham J. Attacking the disease spiral in chronic obstructive pulmonary disease. Clin Med (Lond). 2006;6(2):190-196.

28. Cooper CB. Airflow obstruction and exercise. Respir Med. 2009; 103(3):325-334.

29. Corhay JL, Dang DN, Van Cauwenberge H, Louis R. Pulmonary rehabilitation and COPD: providing patients a good environment for optimizing therapy. Int J Chron Obstruct Pulmon Dis. 2014;9: 27-39.

30. Troosters T, van der Molen T, Polkey M, et al. Improving physical activity in COPD: towards a new paradigm. Respir Res. 2013;14:115.

31. McCarthy B, Casey D, Devane D, Murphy K, Murphy E, Lacasse Y. Pulmonary rehabilitation for chronic obstructive pulmonary disease. Cochrane Database Syst Rev. 2015;(2):CD003793.

32. Huetsch JC, Uman JE, Udris EM, Au DH. Predictors of adherence to inhaled medications among Veterans with COPD. J Gen Intern Med. 2012;27(11):1506-1512.
33. Cecere LM, Slatore CG, Uman JE, et al. Adherence to long-acting inhaled therapies among patients with chronic obstructive pulmonary disease (COPD). COPD. 2012;9(3):251-258.

34. Blackstock FC, ZuWallack R, Nici L, Lareau SC. Why don't our patients with chronic obstructive pulmonary disease listen to us? The enigma of nonadherence. Ann Am Thorac Soc. 2016;13(3):317-323.

35. World Health Organization. Adherence to Long Term Therapies: Evidence for Action. Geneva: World Health Organization; 2003. Available from: http://www.who.int/chp/knowledge/publications/ adherence_report/en/. Accessed December 12, 2016.

36. Mäkelä MJ, Backer V, Hedegaard M, Larsson K. Adherence to inhaled therapies, health outcomes and costs in patients with asthma and COPD. Respir Med. 2013;107(10):1481-1490.

37. Wagg K. Unravelling self-management for COPD: what next? Chron Respir Dis. 2012;9(1):5-7.

38. Sprangers MA, Schwartz CE. Integrating response shift into healthrelated quality of life research: a theoretical model. Soc Sci Med. 1999;48(11):1507-1515.

39. Lee YS, Park S, Oh YM, et al. Chronic obstructive pulmonary disease assessment test can predict depression: a prospective multi-center study. J Korean Med Sci. 2013;28(7):1048-1054.

40. Cleland JA, Lee AJ, Hall S. Associations of depression and anxiety with gender, age, health-related quality of life and symptoms in primary care COPD patients. Fam Prac. 2007;24(3):217-223.

41. Eisner MD, Blanc PD, Yelin EH, et al. Influence of anxiety on health outcomes in COPD. Thorax. 2010;65(3):229-234.

42. Funk GC, Kirchheiner K, Burghuber OC, Hartl S. BODE index versus GOLD classification for explaining anxious and depressive symptoms in patients with COPD - a cross-sectional study. Respir Res. 2009;10:1.

43. Kim KU, Park HK, Jung HY, et al. Association of depression with disease severity in patients with chronic obstructive pulmonary disease. Lung. 2014;192(2):243-249.

44. Ng TP, Niti M, Tan WC, Cao Z, Ong KC, Eng P. Depressive symptoms and chronic obstructive pulmonary disease: effect on mortality, hospital readmission, symptom burden, functional status, and quality of life. Arch Intern Med. 2007;167(1):60-67.

45. Martinez Rivera C, Costan Galicia J, Alcázar Navarrete B, et al. Factors associated with depression in COPD: a multicenter study. Lung. 2016;194(3):335-343.

46. Vanfleteren LE, Spruit MA, Groenen M, et al. Clusters of comorbidities based on validated objective measurements and systemic inflammation in patients with chronic obstructive pulmonary disease. Am J Respir Crit Care Med. 2013;187(7):728-735.

47. Yohannes AM, Willgoss TG, Baldwin RC, Connolly MJ. Depression and anxiety in chronic heart failure and chronic obstructive pulmonary disease: prevalence, relevance, clinical implications and management principles. Int J Geriatr Psychiatry. 2010;25(12):1209-1221.

48. Cindy Ng LW, Mackney J, Jenkins S, Hill K. Does exercise training change physical activity in people with COPD? A systematic review and meta-analysis. Chron Respir Dis. 2012;9(1):17-26.

49. Tödt K, Skargren E, Jakobsson P, Theander K, Unosson M. Factors associated with low physical activity in patients with chronic obstructive pulmonary disease: a cross-sectional study. Scand J Caring Sci. 2015;29(4):697-707.

50. Langhammer A, Johnsen R, Gulsvik A, Holmen TL, Bjermer L. Sex differences in lung vulnerability to tobacco smoking. Eur Respir J. 2003;21(6):1017-1023.

51. Langhammer A, Johnsen R, Holmen J, Gulsvik A, Bjermer L. Cigarette smoking gives more respiratory symptoms among women than among men. The Nord-Trøndelag Health Study (HUNT). J Epidemiol Community Health. 2000;54(12):917-922.

52. Liu Y, Pleasants RA, Croft JB, et al. Smoking duration, respiratory symptoms, and COPD in adults aged $\geq 45$ years with a smoking history. Int J Chron Obstruct Pulmon Dis. 2015;10:1409-1416.

53. Taghizadeh N, Vonk JM, Boezen HM. Lifetime smoking history and cause-specific mortality in a cohort study with 43 years of follow-up. PLoS One. 2016;11(4):e0153310. 
54. Kreuz J, Skowasch D, Kamrath P, et al. Influence of smoking dosage and chronic obstructive lung disease on the incidence of appropriate therapies and mortality in patients with structural heart disease and an implantable cardioverter defibrillator. Pacing Clin Electrophysiol. 2015;38(1):71-76.

55. Nolte S, Elsworth GR, Sinclair AJ, Osborne RH. The extent and breadth of benefits from participating in chronic disease self-management courses: a national patient-reported outcomes survey. Patient Educ Couns. 2007;65(3):351-360.

56. Di Marco F, Verga M, Reggente M, et al. Anxiety and depression in COPD patients: the roles of gender and disease severity. Respir Med. 2006;100(10):1767-1774.

57. Bruce B, Lorig K, Laurent D. Participation in patient self-management programs. Arthritis Rheum. 2007;57(5):851-854.

58. Bode C, De Ridder DT. Investing in the future-identifying participants in an educational program for middle-aged and older adults. Health Educ Res. 2007;22(4):473-482.
59. Dattalo M, Giovannetti ER, Scharfstein D, et al. Who participates in Chronic Disease Self-Management (CDSM) Programs? Differences between participants and non-participants in a population of multimorbid older adults. Med Care. 2012;50(12):1071-1075.

60. Bourbeau J, Collet JP, Schwartzman K, Ducruet T, Nault D, Bradley C. Economic benefits of self-management education in COPD. Chest. 2006;130(6):1704-1711

61. Kirby SE, Dennis SM, Bazeley P, Harris MF. Activating patients with chronic disease for self-management: comparison of self-managing patients with those managing by frequent readmissions to hospital. Aust J Prim Health. 2013;19(3):198-206.

62. Gallant MP. The influence of social support on chronic illness self-management: a review and directions for research. Health Educ Behav. 2003;30(2):170-195.
International Journal of COPD

\section{Publish your work in this journal}

The International Journal of COPD is an international, peer-reviewed journal of therapeutics and pharmacology focusing on concise rapid reporting of clinical studies and reviews in COPD. Special focus is given to the pathophysiological processes underlying the disease, intervention programs, patient focused education, and self management protocols

\section{Dovepress}

This journal is indexed on PubMed Central, MedLine and CAS. The manuscript management system is completely online and includes a very quick and fair peer-review system, which is all easy to use. Visit http://www.dovepress.com/testimonials.php to read real quotes from published authors.

Submit your manuscript here: http://www.dovepress.com/international-journal-of-chronic-obstructive-pulmonary-disease-journal 